\title{
mTOR pathway: A current, up-to-date mini-review (Review)
}

\author{
PAUL ZAROGOULIDIS ${ }^{1}$, SOFIA LAMPAKI ${ }^{1}$, J. FRANCIS TURNER ${ }^{2}$, HAIDONG HUANG $^{3}$, \\ STYLIANOS KAKOLYRIS ${ }^{4}$, KONSTANTINOS SYRIGOS ${ }^{5}$ and KONSTANTINOS ZAROGOULIDIS ${ }^{1}$
}

\author{
${ }^{1}$ Pulmonary Department-Oncology Unit, G. Papanikolaou General Hospital, Aristotle University of Thessaloniki, \\ Thessaloniki 57010, Greece; ${ }^{2}$ Interventional Pulmonary and Critical Care Medicine, Western Regional Medical Center, \\ Goodyear, Arizona 85338, USA; ${ }^{3}$ Department of Respiratory Diseases Shanghai Hospital, Second Military University \\ Hospital, Shanghai 210000, P.R. China; ${ }^{4}$ Oncology Department, University General Hospital of Alexandroupolis, \\ Democritus University of Thrace, Alexandroupolis 68100; ${ }^{5}$ Oncology Department, \\ Sotiria General Hospital, University of Athens, Athens 11527, Greece
}

Received June 2, 2014; Accepted September 26, 2014

DOI: $10.3892 / 01.2014 .2608$

\begin{abstract}
Mammalian target of rapamycin (mTOR) is a protein serine/threonine kinase that was initially identified as the cellular target of rapamycin. This kinase regulates cell growth, proliferation, motility and survival, as well as the gene transcription and protein synthesis that are activated in response to hormones, growth factors and nutrients. Results from preclinical studies have indicated that factors antagonizing the mTOR pathway exert an antitumor effect on lung cancer. Furthermore, primary clinical trials of mTOR inhibitors have demonstrated that the inhibitors may be effective against lung carcinoma. The present study explores the association between mTOR and lung carcinogenesis and describes the clinical trials of mTOR inhibitors.
\end{abstract}

\section{Contents}

1. Introduction

2. The mammalian target of rapamycin pathway

3. Preclinical data

4. Clinical trials

5. Conclusion

\section{Introduction}

Mammalian target of rapamycin (mTOR) is a component of the phosphatidylinositol 3-kinase (PI3K) cell survival pathway that monitors the availability of nutrients, mitogenic signals and cellular energy and oxygen levels, and therefore is

Correspondence to: Dr Paul Zarogoulidis, Pulmonary Department, G. Papanikolaou General Hospital, Aristotle University of Thessaloniki, 1100 Exohi, Thessaloniki 57010, Greece

E-mail: pzarog@hotmail.com

Key words: mTOR, lung cancer, targeted therapy significant in the regulation of cell growth and proliferation (1). Abnormal activation of the PI3K pathway is considered to be involved in numerous cancers, and increased activation of this pathway is often associated with resistance to cancer therapies $(2,3)$. mTOR acts upstream and downstream of Akt, operating at a key junction in the PI3K pathway (4). mTOR can form two different multiprotein complexes, mTORC1 and mTORC2, that regulate the protein synthesis necessary for cell growth and proliferation (4-6). Targeted molecular therapy has an established benefit when combined with platinum-based chemotherapy in phase III randomized trials of patients with metastatic non-small cell lung cancer (NSCLC) (7). Agents targeting vascular endothelial growth factor and epidermal growth factor receptor (EGFR) mimic several novel targeted approaches that improve survival in patients with lung cancer. Tyrosine kinase (TK) inhibitors, including erlotinib and gefitinib, block the intracellular TK domain of EGFR and subsequently cause a blockade of downstream signaling (8). During the process of identifying novel agents, studies have focused on characterizing relevant signaling pathways downstream from surface receptors. A previous study has reported that mTOR is a crucial component of such pathways (9).

\section{The mammalian target of rapamycin pathway}

Ligand-bound activation of one of the transmembrane receptors leads to the activation of PI3K $(10,11)$. PI3K subsequently phosphorylates Akt, which is dephosphorylated by PTEN $(12,13)$. Loss of PTEN is connected with a diminished prognosis in NSCLC, likely due to the enhanced downstream signaling of the PI3K/Akt/mTOR pathway (14). The two mTOR complexes, mTORC1 and mTORC2, are each involved in cell growth $(15,16)$. mTORC1, which consists of mTOR, Raptor, G $\beta \mathrm{L}$ (mammalian lethal with SEC13 protein 8) and domain-containing mTOR-interacting protein (DEPTOR), is partially inhibited by rapamycin (17); it unifies multiple signals that indicate the availability of growth factors, nutrients and energy in order to promote cellular growth and catabolic processes during stress $(18,19)$. Growth factors and hormones, such as insulin, use Akt to signal mTORC1, which 


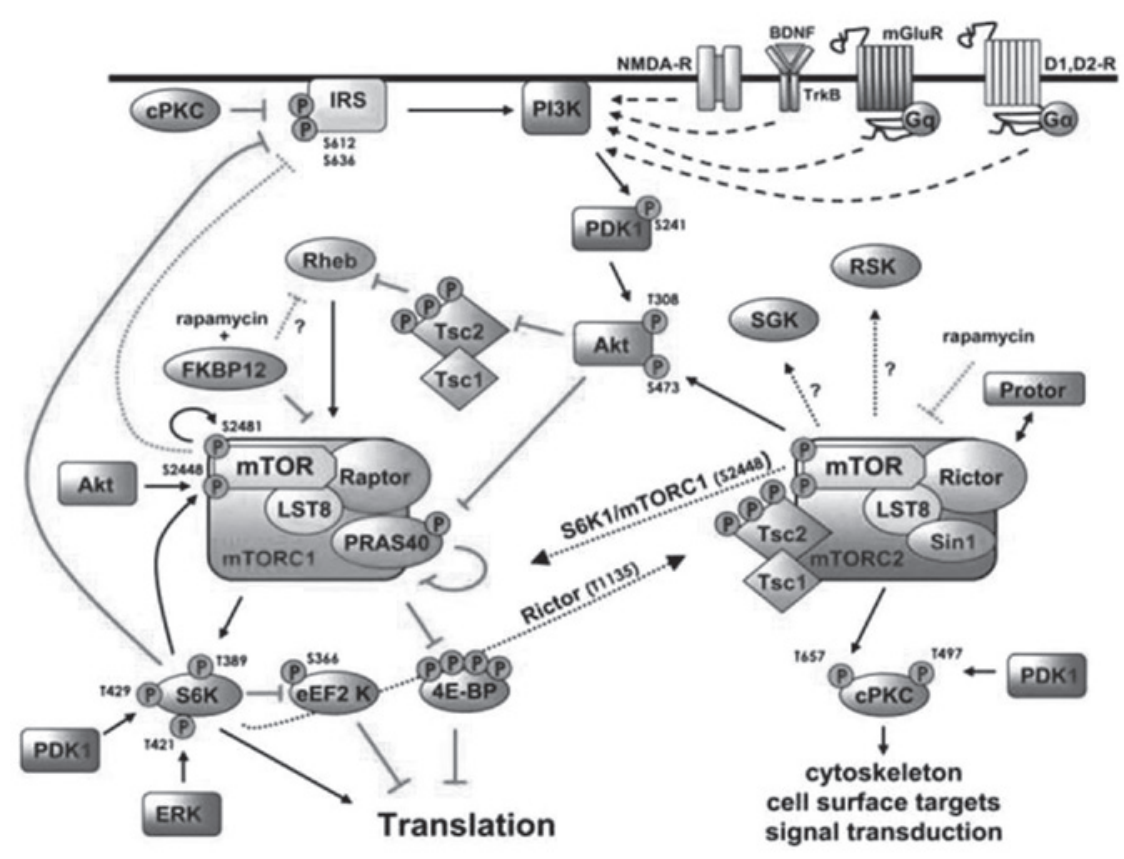

Figure 1. Activation of mammalian target of rapamycin occurs through a complex signaling cascade. mTOR, mammalian target of rapamycin; PI3K, phosphatidylinositol 3-kinase.

inactivates tuberous sclerosis complex 2 to prevent inhibition of mTORC1 (20). Active mTORC1 exerts numerous downstream biological effects, including the translation of mRNA by phosphorylating downstream targets, such as 4E-BP1 and p70 S6 kinase, the suppression of autophagy through Atg13 and ULK1, ribosome biogenesis, and activation of transcription that leads to increased mitochondrial activity or adipogenesis (21-23). mTORC2, which consists of mTOR, Rictor, G $\beta \mathrm{L}$, Sin1, PRR5/Protor-1 and DEPTOR, promotes cell survival through the activation of Akt $(24,25)$. mTORC2 regulates cytoskeletal dynamics, and ion transport and growth by activating PKC $\alpha$ and phosphorylating SGK1, respectively (26-28). mTOR is a downstream target of EGFR and MET signaling, and is therefore considered to be a therapeutically attractive target for the treatment of various types of cancer.

\section{Preclinical data}

Numerous preclinical studies have suggested that mTOR and associated kinases are significant in the development of lung cancer. In a previous study, a spectrum of murine lung tissue was assessed, including normal lung, atypical alveolar hyperplasia, adenoma and adenocarcinoma tissues obtained from K-ras mice (29). Immunohistochemical staining for p-S6 was performed, revealing an elevated level of p-S6 present at each stage of the progression of malignancy. Subsequent studies have suggested that treatment with mTOR inhibitors leads to a reduction in the size and number of early neoplastic lesions. Other studies have investigated the activity of mTOR itself and the upstream regulator Akt (30). Using tissue microarray (TMA) constructs that included $>100$ specimens from patients with NSCLC, positive staining for mTOR was exhibited in $\sim 74 \%$ of tumors. The literature contains data indicating the efficacy of TKIs when EGFR mutations are present, and there are also studies that have reported an involvement of K-ras mutations in conferring resistance to EGFR-targeting monoclonal antibodies (31-35). In an analysis of TMA constructs containing 37 lung tumors, mTOR activation was identified in $89 \%$ of tumors bearing K-ras or EGFR mutations (36). Another preclinical study examined the effect of a combined blockade of MEK and MTOR (37) as MEK activation intersects with mTOR activation at a number of levels. There have been numerous reports of preclinical data that supports the combination of erlotinib with an mTOR inhibitor (38-45). In one study, 22 cell lines from four tumor types, NSCLC, breast, pancreatic and colon tumors, were assessed and it was revealed that mutations in PTEN, EGFR, PI3K and K-ras were present in each cell line (46).

\section{Clinical trials}

Numerous mTOR inhibitors have been revealed to provide antitumor effects in lung cancer. A two-part phase I study assessed the antitumor activity, toxicity and pharmacokinetics of everolimus, administered weekly in 5-30 $\mathrm{mg}$ doses, at increased weekly doses of 50-70 mg and daily administration. In total, 92 patients participated in this study (47), 12 of whom suffered from NSCLC and two from SCLC. Compensatory tolerance of everolimus doses of $\leq 70 \mathrm{mg}$ per week or $10 \mathrm{mg}$ daily was observed. Toxicities, including stomatitis and fatigue, were observed in one patient, dosed at $50 \mathrm{mg}$ per week and hyperglycemia was observed in another patient, dosed at $10 \mathrm{mg}$ per day. Partial responses were observed in four patients and four patients exhibited progression-free survival (PFS) of $\geq 6$ months.

Following this trial, an additional phase II trial enrolled patients with NSCLC into two arms: Arm 1 comprised patients that exhibited a performance status (PS) $<2$ and had failed $<2$ cycles with platinum based therapy and arm 2 comprised patients that had undergone $<2$ cycles of platinum 
based therapy in combination with an EGFR antagonist. These patients were administered everolimus at a dose of $10 \mathrm{mg}$ daily. Partial response (PR) was reported in 5.3\% of arm 1 patients and $2.8 \%$ of arm 2 patients. The median PFS was 11.3 weeks for arm 1 and 9.7 weeks for arm 2 patients. The observed toxicities were stomatitis, cough and dyspnea (48).

Another phase II study investigated patients with SCLC. The patients were free from brain metastasis, had relapsed following one or two regimens and exhibited a PS $<2$. Everolimus was administered until the disease progressed or until the onset of unacceptable toxicity. Of the 16 patients, three exhibited stable disease and the remaining patients exhibited progression. Everolimus was well tolerated, however, the efficacy of the drug was low (49). An additional phase II study assessed the effectiveness of temsirolimus alone in patients with SCLC, following treatment with four or six cycles of platinum-based therapy with etoposide or irinitecan (50). Temsirolimus was intravenously administered weekly at a dose of $25 \mathrm{mg}$ (arm A) and $250 \mathrm{mg}$ (arm B) until disease progression was observed. In 85 patients, the overall survival for arm A was 6.6 months and 9.5 months for arm B.

Deferolimus, a non-prodrug rapamycin analogue, was administered in a phase I trial. In total, 32 patients were administered with 3-28 mg of deferolimus daily. The maximum tolerated dose was $18.75 \mathrm{mg}$. Of the five patients with NSCLC included in the study, only one exhibited PR (51). An additional phase I study assessed treatment with gefitinib and everolimus in patients with progressive NSCLC. Gefitinib was administered at a dose of $250 \mathrm{mg}$ daily and everolimus was administered at a dose of 5-10 mg daily. Of the eight patients evaluated, two exhibited PR (52). Following this, a phase II trial was designed for patients who were previous smokers with stage IIIB/IV NSCLC (53). The study comprised untreated patients (arm A) and patients who had previously received a platinating agent and docetaxel (arm B). PR was observed in 17\% (arm B) of the patients. The toxicities identified were diarrhea, mucositis and rash. In another phase I trial, the combination of everolimus with erlotinib was investigated. This cohort consisted of patients with advanced NSCLC who had previously received two chemotherapy regimens and had an ECOG PS $<2$. Patients were excluded from the trial if they had been previously treated with an EGFR inhibitor. A standard six and six dose escalation design was administered with daily doses of 2.5 and $5 \mathrm{mg}$ and weekly doses of 30 and $40 \mathrm{mg}$ of everolimus, combined with 75 , 100 and $100 \mathrm{mg}$ of erlotinib daily. However, the response data of this trial were moderate (54).

\section{Conclusion}

All of the aforementioned preclinical and clinical trials revealed significant positive results for the use of mTOR antagonists in lung cancer. mTOR expression may be upregulated by numerous mechanisms in the pathogenesis of lung cancer. Furthermore, preclinical data suggests that this class of mTOR pathway antagonists exert an antitumor effect in lung cancer therapy. Consistent with this, initial clinical trials of mTOR inhibitors suggest that they are effective in NSCLC and small cell lung carcinoma therapy. Several phase II and III trials are currently in progress. These additional clinical trials are required to assess the efficacy of mTOR inhibitors as targeted therapy for NSCLC.

\section{References}

1. Liu P, Cheng H, Roberts TM and Zhao JJ: Targeting the phosphoinositide 3-kinase pathway in cancer. Nat Rev Drug Discov 8: 627-644, 2009.

2. Myers AP and Cantley LC: Targeting a common collaborator in cancer development. Sci Transl Med 2: 48ps45, 2010.

3. McCubrey JA, Steelman LS, Franklin RA, et al: Targeting the RAF/MEK/ERK, PI3K/AKT and p53 pathways in hematopoietic drug resistance. Adv Enzyme Regul 47: 64-103, 2007.

4. Vivanco I and Sawyers CL: The phosphatidylinositol 3-kinase-AKT pathway in human cancer. Nat Rev Cancer 2: 489-501, 2002.

5. Bhaskar PT and Hay N: The two TORCs and Akt. Dev Cell 12: 487-502, 2007.

6. Lee DF and Hung MC: All roads lead to mTOR: integrating inflammation and tumor angiogenesis. Cell Cycle 6: 3011-3014, 2007.

7. Pirker R, Pereira JR, Szczesna A, von Pawel J, et al; FLEX study team: Cetuximab plus chemotherapy in patients with advanced non-small-cell lung cancer (FLEX): an open-label randomised phase III trial. Lancet 373: 1525-1531, 2009.

8. Tortora G, Ciardiello F and Gasparini G: Combined targeting of EGFR-dependent and VEGF-dependent pathways: rationale, preclinical studies and clinical applications. Nat Clin Pract Oncol 5: 521-530, 2008

9. Gridelli C, Maione P and Rossi A: The potential role of mTOR inhibitors in non-small cell lung cancer. Oncologist 13: 139-147, 2008.

10. Tokunaga $\mathrm{C}$, Yoshino $\mathrm{K}$ and Yonezawa $\mathrm{K}$ : mTOR integrates amino acid- and energy-sensing pathways. Biochem Biophys Res Commun 313: 443-446, 2004.

11. Beevers CS, Li F, Liu L and Huang S: Curcumin inhibits the mammalian target of rapamycin-mediated signaling pathways in cancer cells. Int J Cancer 119: 757-764, 2006.

12. Huang S and Houghton PJ: Mechanisms of resistance to rapamycins. Drug Resist Updat 4: 378-391, 2001.

13. Huang S, Bjornsti M and Houghton P: Rapamycins: mechanism of action and cellular resistance. Cancer Biol Ther 2: 222-232, 2003.

14. Lazaridis G, Lambaki S, Karayannopoulou G, et al: Prognostic and predictive value of p-Akt, EGFR, and p-mTOR in early breast cancer. Strahlenther Onkol 190: 636-638, 640-645.

15. Wullschleger S, Loewith $\mathrm{R}$ and Hall MN: TOR signaling in growth and metabolism. Cell 124: 471-484, 2006.

16. Betz C and Hall MN: Where is mTOR and what is it doing there? J Cell Biol 203: 563-574, 2013.

17. Kim DH, Sarbassov DD, Ali SM, King JE, Latek RR, Erdjument-Bromage H, Tempst P and Sabatini DM: mTOR interacts with raptor to form a nutrient-sensitive complex that signals to the cell growth machinery. Cell 110: 163-175, 2002.

18. Kim DH, Sarbassov DD, Ali SM, Latek RR, Guntur KV, Erdjument-Bromage H, Tempst P and Sabatini DM: GbetaL, a positive regulator of the rapamycin-sensitive pathway required for the nutrient-sensitive interaction between raptor and mTOR. Mol Cell 11: 895-904, 2003.

19. Fang Y, Vilella-Bach M, Bachmann R, Flanigan A and Chen J: Phosphatidic acid-mediated mitogenic activation of mTOR signaling. Science 294: 1942-1945, 2001

20. Frias MA, Thoreen CC, Jaffe JD, Schroder W, Sculley T, Carr SA and Sabatini DM: mSin1 is necessary for Akt/PKB phosphorylation, and its isoforms define three distinct mTORC2s. Curr Biol 16: 1865-1870, 2006.

21. Sarbassov DD, Ali SM, Kim DH, Guertin DA, Latek RR, Erdjument-Bromage H, Tempst P and Sabatini DM: Rictor, a novel binding partner of mTOR, defines a rapamycin-insensitive and raptor-independent pathway that regulates the cytoskeleton. Curr Biol 14: 1296-1302, 2004.

22. Betz C, Stracka D, Prescianotto-Baschong C, Frieden M, Demaurex N and Hall MN: Feature Article: mTOR complex 2-Akt signaling at mitochondria-associated endoplasmic reticulum membranes (MAM) regulates mitochondrial physiology. Proc Natl Acad Sci USA 110: 12526-12534, 2013.

23. Sarbassov DD, Guertin DA, Ali SM and Sabatini DM: Phosphorylation and regulation of $\mathrm{Akt} / \mathrm{PKB}$ by the rictor-mTOR complex. Science 307: 1098-1101, 2005.

24. Stephens L, Anderson K, Stokoe D, Erdjument-Bromage H, Painter GF, Holmes AB, Gaffney PR, Reese CB, McCormick F, Tempst P, Coadwell J and Hawkins PT: Protein kinase B kinases that mediate phosphatidylinositol 3,4,5-trisphosphate-dependent activation of protein kinase B. Science 279: 710-714, 1998. 
25. Lamming DW, Ye L, Katajisto P, Goncalves MD, Saitoh M, Stevens DM, Davis JG, Salmon AB, Richardson A, Ahima RS, Guertin DA, Sabatini DM and Baur JA: Rapamycin-induced insulin resistance is mediated by mTORC2 loss and uncoupled from longevity. Science 335: 1638-1643, 2012.

26. Tang JM, He QY, Guo RX and Chang XJ: Phosphorylated Akt overexpression and loss of PTEN expression in non-small cell lung cancer confers poor prognosis. Lung Cancer 51: 181-191, 2006.

27. Dowling RJ, Topisirovic I, Fonseca BD and Sonenberg N: Dissecting the role of mTOR: lessons from mTOR inhibitors Biochim Biophys Acta 1804: 433-439, 2010.

28. Dunlop EA and Tee AR: Mammalian target of rapamycin complex 1: signalling inputs, substrates and feedback mechanisms. Cell Signal 21: 827-835, 2009.

29. Wislez M, Spencer ML, Izzo JG, et al: Inhibition of mammalian target of rapamycin reverses alveolar epithelial neoplasia induced by oncogenic K-ras. Cancer Res 65: 3226-3235, 2005.

30. Balsara BR, Pei J, Mitsuuchi Y, Page R, et al: Frequent activation of AKT in non-small cell lung carcinomas and preneoplastic bronchial lesions. Carcinogenesis 25: 2053-2059, 2004.

31. Amado RG, Wolf M, Peeters M, et al: Wild-type KRAS is required for panitumumab efficacy in patients with metastatic colorectal cancer. J Clin Oncol 26: 1626-1634, 2008.

32. Sarosi V,Losonczy G, Francovszky E, Tolnay E, Torok S, Galffy G Hegedus B, Dome B and Ostoros G: Effectiveness of erlotinib treatment in advanced KRAS mutation-negative lung adenocarcinoma patients: Results of a multicenter observational cohort study (MOTIVATE). Lung Cancer 86: 54-58, 2014.

33. Gridelli C, de Marinis F, Cappuzzo F, et al: Treatment of advanced non-small-cell lung cancer with epidermal growth factor receptor (EGFR) mutation or ALK gene rearrangement: results of an international expert panel meeting of the Italian Association of Thoracic Oncology. Clin Lung Cancer 15: 173-181, 2014.

34. Laurent-Puig P, Pekin D, Normand C, K Kotsopoulos S, Nizard P, Perez Toralla K, Rowell R, Olson J, Srinivasan P, Le Corre D, et al: Clinical relevance of KRAS-mutated sub-clones detected with picodroplet digital PCR in advanced colorectal cancer treated with anti-EGFR therapy. Clin Cancer Res: Sep 23, 2014 (Epub ahead of print).

35. Choughule A, Sharma R, Trivedi V, Thavamani A, Noronha V, Joshi A, Desai S, Chandrani P, Sundaram P, Utture S, et al: Coexistence of KRAS mutation with mutant but not wild-type EGFR predicts response to tyrosine-kinase inhibitors in human lung cancer. Br J Cancer: Aug 12, 2014 (Epub ahead of print).

36. Conde E, Angulo B, Tang M, et al: Molecular context of the EGFR mutations: evidence for the activation of $\mathrm{mTOR} / \mathrm{S} 6 \mathrm{~K}$ signaling. Clin Cancer Res 12: 710-717, 2006.

37. Legrier ME, Yang CP, Yan HG, et al: Targeting protein translation in human non small cell lung cancer via combined MEK and mammalian target of rapamycin suppression. Cancer Res 67 11300-11308, 2007.

38. Buck E, Eyzaguirre A, Brown E, et al: Rapamycin synergizes with the epidermal growth factor receptor inhibitor erlotinib in non-small-cell lung, pancreatic, colon, and breast tumors. Mol Cancer Ther 5: 2676-2684, 2006.

39. Glaysher S, Bolton LM, Johnson P, Torrance C and Cree IA Activity of EGFR, mTOR and PI3K inhibitors in an isogenic breast cell line model. BMC Res Notes 7: 397, 2014

40. Jänne PA, Cohen RB, Laird AD, et al: Phase I safety and pharmacokinetic study of the PI3K/mTOR inhibitor SAR245409 (XL765) in combination with erlotinib in patients with advanced solid tumors. J Thorac Oncol 9: 316-323, 2014.

41. Wen PY, Chang SM, Lamborn KR, Kuhn JG, Norden AD, Cloughesy TF, Robins HI, Lieberman FS, Gilbert MR, Mehta MP, et al: Phase I/II study of erlotinib and temsirolimus for patients with recurrent malignant gliomas: North American Brain Tumor Consortium trial 04-02. Neuro Oncol 16: 567-578, 2014.
42. Wang Q, Wei F, Li C, Lv G, Wang G, Liu T, Bellail AC and Hao C: Combination of mTOR and EGFR kinase inhibitors blocks mTORC1 and mTORC2 kinase activity and suppresses the progression of colorectal carcinoma. PLoS One 8: e73175, 2013.

43. Bauman JE, Arias-Pulido H, Lee SJ, Fekrazad MH, Ozawa H, Fertig E, Howard J, Bishop J, Wang H, Olson GT, et al: A phase II study of temsirolimus and erlotinib in patients with recurrent and/or metastatic, platinum-refractory head and neck squamous cell carcinoma. Oral Oncol 49: 461-467, 2013.

44. Papadimitrakopoulou VA, Soria JC, Jappe A, Jehl V, Klimovsky $\mathrm{J}$ and Johnson BE: Everolimus and erlotinib as second- or third-line therapy in patients with advanced non-small-cell lung cancer. J Thorac Oncol 7: 1594-1601, 2012.

45. Bago-Horvath Z, Sieghart W, Grusch M, Lackner A, Hayden H, Pirker C, Komina O, Wesierska-Gadek J, Haitel A, Filipits M, et al: Synergistic effects of erlotinib and everolimus on bronchial carcinoids and large-cell neuroendocrine carcinomas with activated EGFR/AKT/mTOR pathway. Neuroendocrinology 96: 228-237, 2012.

46. Matar P, Rojo F, Cassia R, et al: Combined epidermal growth factor receptor targeting with the tyrosine kinase inhibitor gefitinib (ZD1839) and the monoclonal antibody cetuximab (IMC-C225): superiority over single-agent receptor targeting. Clin Cancer Res 10: 6487-6501, 2004.

47. O'Donnell A1, Faivre S, Burris HA III, et al: Phase I pharmacokinetic and pharmacodynamic study of the oral mammalian target of rapamycin inhibitor everolimus in patients with advanced solid tumors. J Clin Oncol 26: 1588-1595, 2008

48. Besse B, Leighl N, Bennouna J, et al: Phase II study of everolimus-erlotinib in previously treated patients with advanced non-small-cell lung cancer. Ann Oncol 25: 409-415, 2014.

49. Owonikoko TK, Stoller RG, Petro D, et al: Phase II study of RAD001 (Everolimus) in previously treated small cell lung cancer (SCLC). J Clin Oncol 26 (Suppl 15): 19017, 2008.

50. Pandya KJ, Dahlberg S, Hidalgo M, et al; Eastern Cooperative Oncology Group (E1500): A randomized, phase II trial of two dose levels of temsirolimus (CCI-779) in patients with extensive-stage small-cell lung cancer who have responding or stable disease after induction chemotherapy: a trial of the Eastern Cooperative Oncology Group (E1500). J Thorac Oncol 2: 1036-1041, 2007.

51. Mita MM, Mita AC, Chu QS, et al: Phase I trial of the novel mammalian target of rapamycin inhibitor deforolimus (AP23573; MK-8669) administered intravenously daily for 5 days every 2 weeks to patients with advanced malignancies. J Clin Oncol 26: 361-367, 2008.

52. Milton DT, Riely GJ, Azzoli CG, et al: Phase 1 trial of everolimus and gefitinib in patients with advanced nonsmall-cell lung cancer. Cancer 110: 599-605, 2007.

53. Riely GJ, Kris MG, Zhao B, et al: Prospective assessment of discontinuation and reinitiation of erlotinib or gefitinib in patients with acquired resistance to erlotinib or gefitinib followed by the addition of everolimus. Clin Cancer Res 13: 5150-5155, 2007.

54. Papadimitrakopoulou V, Blumenschein GR Jr, Leighl NB, et al: A phase $1 / 2$ study investigating the combination of RAD0001 (everolimus) and erlotinib $(\mathrm{E})$ as 2nd and 3rd line therapy in patients (pts) with advanced non-small cell lung cancer (NSCLC) previously treated with chemotherapy (C): phase 1 results. J Clin Oncol 26 (Suppl 15): 8051, 2008. 